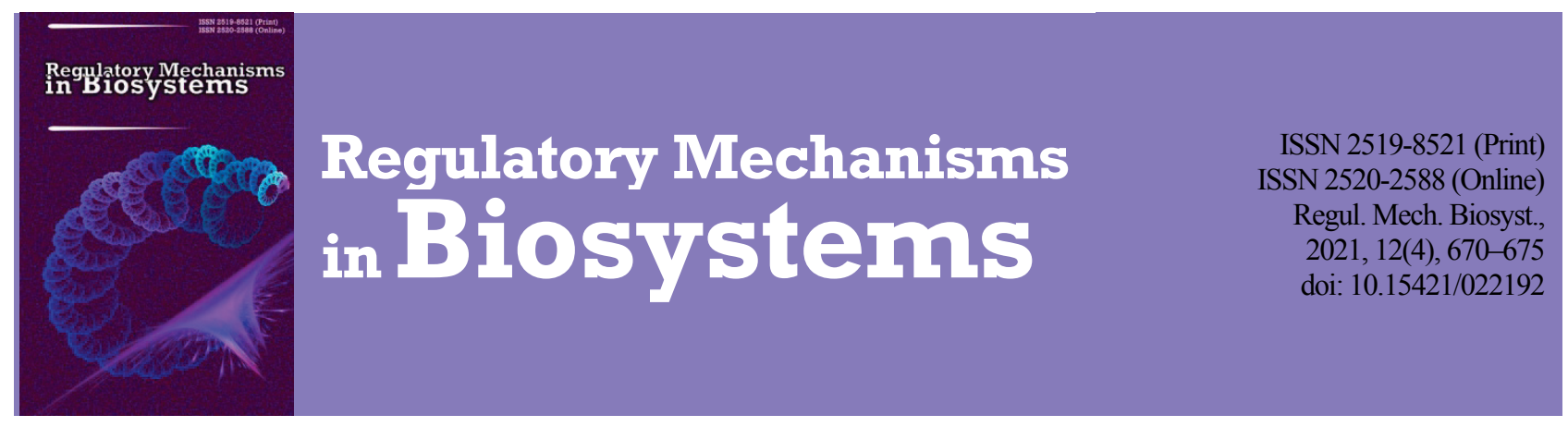

\title{
Splenomegaly development and disseminated intravascular coagulation syndrome in acute canine babesiosis
}

\author{
O. A. Dubova*, D. V. Feshchenko*, T. I. Bakhur**, A. A. Dubovyi*, O. A. Zghozinska*, I. V. Chala* \\ *Polissia National University, Zhytomyr, Ukraine \\ **Bila Tserkva National Agrarian University, Bila Tserkva, Ukraine
}

Article info

Received 29.09.2021

Received in revised form 20.10 .2021

Accepted 21.10.2021

Dubova, O. A., Feshchenko, D. V., Bakhur, T. I., Dubovyi, A. A., Zghozinska, O. A., \& Chala, I. V. (2021). Splenomegaly development and disseminated intravascular coagulation syndrome in acute canine babesiosis. Regulatory Mechanisms in Biosystems, 12(4), 670675. doi:10.15421/022192

Polissia National

University,

Staryi blvd., 7,

Zhytomyr,

10002, Ukraine.

Tel.: +38-098-525-97-18.

E-mail:dolly-d@i.ua

Disseminated intravascular coagulation (DIC) syndrome is the main defining process in the pathogenetic axis of complications in canine babesiosis. The involvement of the spleen with further irreversible changes in the organ largely determines the severity of the animal's condition after spontaneous babesiosis. The work presented here aimed to determine the role of the DIC syndrome as a triggering factor for lesions of the spleen. Clinical and laboratory studies (haematological, biochemical, hemodynamic) have been carried out. Pathological studies of the removed spleen were carried out by histological methods using universal and specific staining. After suffering acute spontaneous babesiosis, the development of hypersplenism and splenomegaly was found in dogs. The diagnosis was confirmed haematologically by the detected cytopenia, normochromic type anaemia. An additional parameter was a significantly increased erythrocyte sedimentation rate. The biochemical profile indicated the development of bilirubinaemia due to the conjugated fraction, hyperfermentation of transaminases, hypoalbuminemia, which reflected the development of hepatitis and liver failure. Markers of DIC syndrome in laboratory studies are represented by reliable hypofibrinogenemia, increased level of fibrinogen/fibrin degradation products, including D-dimer, and soluble fibrin monomer complexes. The multidirectional indices of coagulation tests (activated partial thromboplastin and prothrombin time) made it possible to classify the stage of "consumption coagulopathy" of the DIC syndrome. The haemodynamic parameters of the sick dogs were characterized by a significant deficit in the circulating blood volume. Together with the indicators of the "consumption coagulopathy" stage of the DIC syndrome, the hemodynamic indexes indicate a moderate degree of shock stage II - the stable reversibility, but the magnitude of the circulating blood volume deficit determines the tendency towards shock irreversibility. Histological studies have established a significant proliferation of the stromal elements of the organ, the formation of specific complexes of vessels with sinuses, clogging with blood clots, and the organ's parenchyma dystrophy. Such changes characterize complete splenomegaly, which is based on the organo-pathology of the DIC syndrome. The deposition of "old" fibrin in the connective tissue structures of the spleen indicates that DIC syndrome continues throughout the entire period of hyperplastic changes in the organ. The presence of hyalinosis in blood vessel walls of the spleen parenchyma determines irreversible changes in them. Thus, DIC syndrome is the basis for splenomegaly development in dogs after acute spontaneous babesiosis. It is confirmed by laboratory blood tests and histologically by the presence of fibrin thrombi in the structures of the organ, which determine the organopathology of the syndrome. The information obtained serves to expand the concepts of the pathogenesis of blood protozoal disease, define the high risk of complications that can become fatal for the health and life of animals.

Keywords: hypersplenism; cytopenia; fibrin age; organopathology of DIC; shock; circulating blood volume; markers of DIC syndrome; consumption coagulopathy.

\section{Introduction}

Canine babesiosis is a typical enzootic protozoal disease for the Central Polissia zone of Ukraine. Its causative agents are large forms of Babesia spp. (B. canis Piana et Galli-Valerio, 1895, B. vogeli Reichenow, 1937), which are distinguished by interspecific virulence. Regional vectors of babesiosis are ixodid ticks of some species from genera Dermacentor Koch, 1844 and Ixodes Latreille, 1795 (Vannier and Krause, 2013; Köster et al., 2015; Pantchev et al., 2015; Solano-Gallego et al., 2016; Akel \& Mobarakai, 2017; Bilić et al., 2018; Wahlang et al., 2019; Vishwakarma \& Nandini, 2019).

Babesiae are intra-erythrocytic parasites. Therefore, the symptoms of babesiosis are characterized by clinical signs of damage to various organs and systems as a result of their oxygen starvation. Also, Babesia spp. have toxic, allergic, trophic, and inoculation pathogenic effects on the host organism (Schetters et al., 2009; Köster et al., 2015; Eichenberger et al., 2016). The involvement of various organs and systems of a sick animal in the pathological process of babesiosis is subject to a single pathogenetic axis the development of disseminated intravascular coagulation (DIC) syndrome. The genesis of DIC syndrome is based on the fibrin thrombus formation mainly in the area of the microvasculature (Goddard et al., 2013; Goddard et al., 2016; Dubova et al., 2020). Further, as a result of depletion of blood coagulation factors, bleeding occurs. The central link in the chain of these pathological phenomena is the defeat of a vascular endothelium under the influence of the primary parasitic factor (Goddard et al., 2013).

Babesiae, which initially entered the dog's body, are retained in cells of the mononuclear phagocyte system or bound by hepatocyte receptors. Mass hepatocyte destruction occurs due to the multiplication of trophozoites in hepatocytes. Parasites have a destructive effect on liver vessels and an entire portal system, as a result of which portal hypertension occurs (Schetters et al., 2009; Köster et al., 2015; Dubova et al., 2019).

Affected erythrocytes are utilized by the spleen. The function of the organ in the initial stage of babesiosis is intensively activated, which to some extent is also caused by increased pressure in the portal vein (Boes 
\& Durham, 2017; Dubova et al., 2019). Further, other blood cells also fall under utilization, which determines the development of pronounced hypersplenism (Warkentin, 2018). In the end, the spleen parenchyma under the influence of babesia toxins and metabolites dies and is replaced by connective tissue. The elements of the mononuclear phagocyte system are subject to degeneration. As a result, in dogs affected by Babesia spp. irreversible splenomegaly occurs (Mohapatra \& Mishra, 2013; Dubova et al., 2019).

The current work aimed at determining the role of DIC syndrome in the development of irreversible splenomegaly in acute spontaneous canine babesiosis.

\section{Materials and methods}

The research was carried out at the Educational-Scientific-Production Clinic of Veterinary Medicine of the Polissia National University (Zhytomyr, Ukraine) during 2018-2020. The research protocol of the current study was approved by the Ethics Committee of the Polissia National University (approval number 2018/05). The experimental group consisted of 25 dogs of different breeds and crosses of breeds, aged from 2 to 7 years, weighing $10-40 \mathrm{~kg}$, which, after suffering spontaneous babesiosis, had complications in the form of hypersplenism and splenomegaly. Control group - clinically healthy $\operatorname{dogs}(\mathrm{n}=30)$.

Animals with babesiosis were treated according to the traditional protocol using the antiprotozoal drug Piro-stop ${ }^{\circledR}$ (NPO Api-San LLC, Russian Federation), as well as pathogenetic and symptomatic therapy.

Complicated splenomegaly was diagnosed 7-10 days after clinical recovery in dogs initially infected with Babesia spp.

Clinical studies were carried out using general methods. The final diagnosis of babesiosis was established based on the detection of intraerythrocytic paired-pear-shaped form parasites in fixed blood smears (Giemsa stain) (Briggs \& Bain, 2017), which were identified as large forms of Babesia spp. The average intensity of parasitaemia in the experimental dogs was $6-10 \%$ of affected erythrocytes.

Ultrasound examination was performed using a SonoScape S 20 apparatus with a Doppler (SonoScape Medical Corp., P. R. China). Fixation of dogs was in dorsal recumbency, and in some cases - lateral right-sided. The sensor frequency was 5-10 MHz. The size, boundaries of the spleen topographic position, echogenicity, as well as spleen parenchyma echostructure were determined (Tutton et al., 2008; Nyland \& Mattoon, 2015).

Haematological studies (haemoglobin content, erythrocyte sedimentation rate (ESR), the number of erythrocytes, leukocytes and platelets) were performed on a Mindray BC-3600 (Mindray Medical Rus Co. Ltd, Russian Federation) haematology analyser (Briggs \& Bain, 2017).

Hemodynamic parameters included determining the circulating blood volume $(\mathrm{CBV})$ and its components using the method of dilution (Soroka, N. M., Dubova, O. A., \& Iaremenko, D. O. (2005). A method of determining the volume of circulating blood in dogs. UA Patent 10707) of the T-1824 dye Evans blue, as well as calculating the specific volume of circulating blood (mL/kg) (Schorn, 2010; Nathan et al., 2016; Belousov, 2017). The deficiency of CBV was determined by the Moore haematocrit method according to the formula (1):

$$
B L V=C B V_{\text {norm }} \times \frac{\left(H t_{\text {norm }}-H t_{\text {researc } h}\right)}{H t_{\text {norm }}}
$$

BLV - blood loss volume (mL), CBV - normal circulating blood volume $(\mathrm{mL}), \mathrm{Ht}_{\text {nom }}$ - normal haematocrit $(\mathrm{L} / \mathrm{L}), \mathrm{Ht}_{\text {research }}$ - haematocrit value of patients $(\mathrm{L} / \mathrm{L})$.

For biochemical studies (total protein and albumin amount, activity of transaminases ALT, AST, GGT, total and conjugated bilirubin concentration), a semi-automatic biochemical analyser RT-9100 Vet (Rayto Life and Analytical Sciences Co., Ltd., P. R. China) was used.

Coagulographic parameters - soluble fibrin-monomer complexes (SFMC), amount of fibrinogen and fibrinogen/fibrin degradation products (FDP) (Rafaj et al., 2013; Nguyen et al., 2016; Laffan \& Manning, 2017; Kawasugi et al., 2021), as well as thrombocytopenia, served as indicators of the development of DIC syndrome in canine babesiosis (Jobe \& Di Paola, 2019; Michelson, 2019).

The SFMC content was determined by a quantitative version of the ortho-phenanthroline method (Rafaj et al., 2013). Fibrinogen levels were assessed by the Claus clotting method using a coagulometer ACL TOP
350 CTS (Instrumentation Laboratory, USA) (Briggs \& Bain, 2017) as well as activated partial thromboplastin time (APTT) and prothrombin time (PT) of blood plasma (Roshal, 2013a, 2013b). The content of FDP and D-dimer were determined by enzyme-linked immunosorbent assay (Rafaj et al., 2013). Spleens were removed during a forced splenectomy. The dimensions of the organ were measured, the nature of the surface, consistency and internal structure were assessed.

For histological studies, pieces of the spleen from different areas were embedded in paraffin. Sections were stained with hematoxylin-eosin and by the red-blue-black method (RBB) (Soroka, N. M., \& Dubova, O. A. (2004). A method for determination of fibrin in disseminated intravascular coagulation syndrome. UA Patent 7324).

Histological preparations were photographed using a Levenhuk MED 35 microscope with a Levenhuk M Plus digital camera (Levenhuk Zoom \& Joy, Russian Federation).

Statistical processing was performed by a multiple comparison of variances using the Fisher distribution (ANOVA). Calculations were performed using Statistica 13.3 IT Application. The obtained data significance was assessed by Fisher's F-test at a confidence level $\mathrm{P}<0.05$.

\section{Results}

In sick dogs with the primary course of spontaneous babesiosis on the first day of observation, the following were noted: decrease or loss of appetite, lethargy, fever $\left(40-41^{\circ} \mathrm{C}\right)$, anaemicity of visible mucous membranes, bloody urine. In the next 3 days, yellowness of the mucous membranes appeared, reflected pain in the right hypochondrium, a single portion of urine was reduced by three times. Vomiting of foam with bile impurities was accompanied by various disorders of the gastrointestinal tract - from flatulence and constipation to diarrhoea. All dogs diagnosed with babesiosis had tachycardia and dyspnoea. Movement coordination disorders and clonic-tonic seizures were noted in $8 \%$ of affected dogs.

After the traditional treatment, the patients recovered within 3-5 days.

Signs of deteriorating health appeared in 25 dogs (8.3\%) 7-10 days after clinical recovery. Symptoms were manifested by a decrease or loss of appetite, apathy, and the development of expiratory dyspnoea. Vomiting and intestinal flatulence were noted in $14 \operatorname{dogs}(56 \%)$.

Palpation of the abdominal wall revealed an increase in the spleen in the left hypochondrium, which was pronounced in the epigastric region. The pain sensitivity was exacerbated. In the area of the right hypochondrium, an enlarged caudal edge of the liver was palpable.

According to the results of the ultrasonographic examination, it was found that the enlarged spleen was located in the centre of the abdominal cavity, in the pre-umbilical region, and the region of the xiphoid cartilage. The spleen caudicle was placed caudal to the navel, which in 8 cases reached the bladder zone. The organ had rounded edges, uneven borders. There were thickenings in the middle and caudal part of the spleen. The parenchyma of the organ had a reduced echogenicity, its structure was heterogeneous. The foci of reduced echogenicity or its absence did not have clear boundaries.

In the study of blood, complex changes were established (Tables 1-4). From the data presented, it can be seen that the sick animals had pronounced cytopenia, bilirubinaemia developed due to the predominantly conjugated fraction, the activity of transaminases was increased; as well as hypoalbuminemia, hypofibrinogenemia, an increase in FDP including D-dimer, and SFMC levels were noted. There was a significant decrease in specific CBV by 1.6 times, the CBV deficit was $41 \%$.

\section{Table 1}

Haematologic parameters in dogs with manifestations of hypersplenism after the acute spontaneous babesiosis $(\mathrm{x} \pm \mathrm{SE})$

\begin{tabular}{lcr}
\hline \multicolumn{1}{c}{ Indicators } & $\begin{array}{c}\text { Control } \\
\text { group }(\mathrm{n}=30)\end{array}$ & $\begin{array}{r}\text { Experimental } \\
\text { group }(\mathrm{n}=25)\end{array}$ \\
\hline Haemoglobin, $\mathrm{g} / \mathrm{L}$ & $124.6 \pm 5.3$ & $72.3 \pm 6.2^{* * *}$ \\
Erythrocyte sedimentation rate, $\mathrm{mm} / \mathrm{h}$ & $2.8 \pm 0.1$ & $24.8 \pm 3.8^{* * *}$ \\
Erythrocytes, $\mathrm{T} / \mathrm{L}$ & $6.3 \pm 0.3$ & $3.0 \pm 0.4^{* * *}$ \\
Leukocytes, $\mathrm{G} / \mathrm{L}$ & $12.0 \pm 0.4$ & $5.2 \pm 0.9^{* * *}$ \\
Platelets, $\mathrm{G} / \mathrm{L}$ & $286.0 \pm 10.3$ & $170.0 \pm 9.3^{* * *}$ \\
\hline
\end{tabular}

Note: ${ }_{-} \mathrm{P}<0.05 ; * *-\mathrm{P}<0.01 ; * * *-\mathrm{P}<0.001$ relative to the control group. 
The data of coagulographic tests tended to be multidirectional indicators - APTT decreases, while PT lengthens. The removed spleen visually had the following anatomical characteristics: rounded edges; lumpy flabby surface; the left part was thickened, and it was 1.5-2.0 times greater than the thickness of the right part. The consistency of the organ was dense, the colour was purple-cyanotic. The capsule was loose, cloudy. Vessels were filled with blood.

Table 2

Hemodynamic parameters of dogs with manifestations of hypersplenism after the acute spontaneous babesiosis $(\mathrm{x} \pm \mathrm{SE})$

\begin{tabular}{lcc}
\hline \multicolumn{1}{c}{ Indicators } & $\begin{array}{c}\text { Control } \\
\text { group }(\mathrm{n}=30)\end{array}$ & $\begin{array}{c}\text { Experimental } \\
\text { group }(\mathrm{n}=25)\end{array}$ \\
\hline Haematocrit, $\mathrm{L} / \mathrm{L}$ & $0.46 \pm 0.04$ & $0.27 \pm 0.06^{* *}$ \\
Circulating plasma volume, $\mathrm{mL}$ & $2739.0 \pm 108.3$ & $2446.0 \pm 203.8$ \\
Circulating erythrocytes volume, $\mathrm{mL}$ & $2254.0 \pm 180.5$ & $928.0 \pm 70.0^{*}$ \\
Circulating blood volume, $\mathrm{mL}$ & $5102.0 \pm 138.1$ & $3428.0 \pm 327.0^{* * *}$ \\
Specific circulating blood volume, $\mathrm{mL} / \mathrm{kg}$ & $128.0 \pm 6.4$ & $87.4 \pm 5.1^{* * *}$ \\
Circulating blood volume, & $13.2 \pm 0.6$ & $8.5 \pm 0.3^{* * *}$ \\
\% of body weight & &
\end{tabular}

Note: $* * *-\mathrm{P}<0.001, *-\mathrm{P}<0.05$ relative to the control group.

Table 3

Biochemical indicators of dogs with manifestations

of hypersplenism after the acute spontaneous babesiosis $(x \pm S E)$

\begin{tabular}{lcc}
\hline \multicolumn{1}{c}{ Indicators } & $\begin{array}{c}\text { Control } \\
\text { group }(\mathrm{n}=30)\end{array}$ & $\begin{array}{c}\text { Experimental } \\
\text { group }(\mathrm{n}=25)\end{array}$ \\
\hline Total bilirubin, $\mu \mathrm{mol} / \mathrm{L}$ & $4.3 \pm 0.06$ & $17.7 \pm 3.2^{* * *}$ \\
Conjugated bilinubin, $\mu \mathrm{mol} / \mathrm{L}$ & 0 & $9.6 \pm 2.2^{* * *}$ \\
Aspartate aminotransferase, IU/L & $16.4 \pm 0.8$ & $98.3 \pm 8.6^{* * *}$ \\
Alanine aminotransferase, IU/L & $21.2 \pm 1.4$ & $106.0 \pm 12.3^{* * *}$ \\
Gamma glutamyltransferase, IU/L & $2.3 \pm 0.8$ & $26.3 \pm 5.6^{* * *}$ \\
Total protein, g/L & $73.4 \pm 4.4$ & $64.1 \pm 4.8$ \\
Albumin, g/L & $34.7 \pm 2.1$ & $20.1 \pm 2.2^{* * *}$ \\
Soluble fibrin-monomer complexes, $\mathrm{g} / \mathrm{L}$ & $0.030 \pm 0.002$ & $0.310 \pm 0.014^{* * *}$ \\
Fibrinogen/fibrin degradation products, $\mathrm{g} / \mathrm{L}$ & $0.078 \pm 0.010$ & $0.34 \pm 0.04^{* * *}$ \\
Fibrinogen, g/L & $2.65 \pm 0.19$ & $0.38 \pm 0.26^{* * *}$ \\
\hline
\end{tabular}

Note: ${ }^{*}-\mathrm{P}<0.05 ; * *-\mathrm{P}<0.01 ; * * *-\mathrm{P}<0.001$ relative to the control group.

Table 4

Markers of intravascular coagulation in dogs with hypersplenism after acute spontaneous babesiosis $(\mathrm{x} \pm \mathrm{SE})$

\begin{tabular}{lcc}
\hline \multicolumn{1}{c}{ Indicators } & $\begin{array}{c}\text { Control } \\
\text { group }(\mathrm{n}=30)\end{array}$ & $\begin{array}{c}\text { Experimental } \\
\text { group }(\mathrm{n}=25)\end{array}$ \\
\hline Soluble fibrin-monomer complexes, $\mathrm{g} / \mathrm{L}$ & $0.030 \pm 0.002$ & $0.310 \pm 0.014^{* * *}$ \\
$\mathrm{FDP}, \mathrm{g} / \mathrm{L}$ & $0.078 \pm 0.001$ & $0.34 \pm 0.04^{* * *}$ \\
$\mathrm{D}-$-dimer, $\mu \mathrm{g} / \mathrm{L}$ & $0.17 \pm 0.02$ & $0.62 \pm 0.12^{* * *}$ \\
Fibrinogen, $\mathrm{g} / \mathrm{L}$ & $2.65 \pm 0.19$ & $0.38 \pm 0.26^{* * *}$ \\
Activated partial thromboplastin time of plasma, $\mathrm{s}$ & $44.4 \pm 2.8$ & $39.8 \pm 5.4$ \\
Prothrombin time of plasma, $\mathrm{s}$ & $19.3 \pm 1.1$ & $23.5 \pm 1.2$ \\
\hline
\end{tabular}

Note: ***- $\mathrm{P}<0.001$ relative to the control group.

Histological examination revealed that the white pulp was poorly structured, the lymphatic formations were not expressed (Fig. 1).

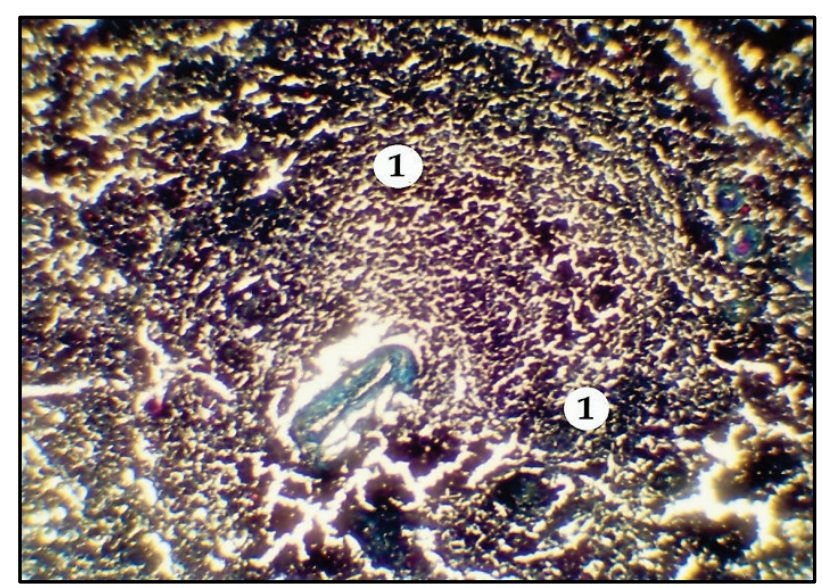

Fig. 1. The lymphatic follicle of the spleen in canine splenomegaly: 1 - poorly expressed structure; RBB stain. $\times 100$
The trabeculae were thickened and destructed. The strong proliferation of blood vessels formed specific complexes with the sinuses, forming the cavernous bodies. These complexes were sufficiently developed and displaced the pulp. Blood clots were noted in the vascular lumen which completely obstructed vessels (Fig. 2).

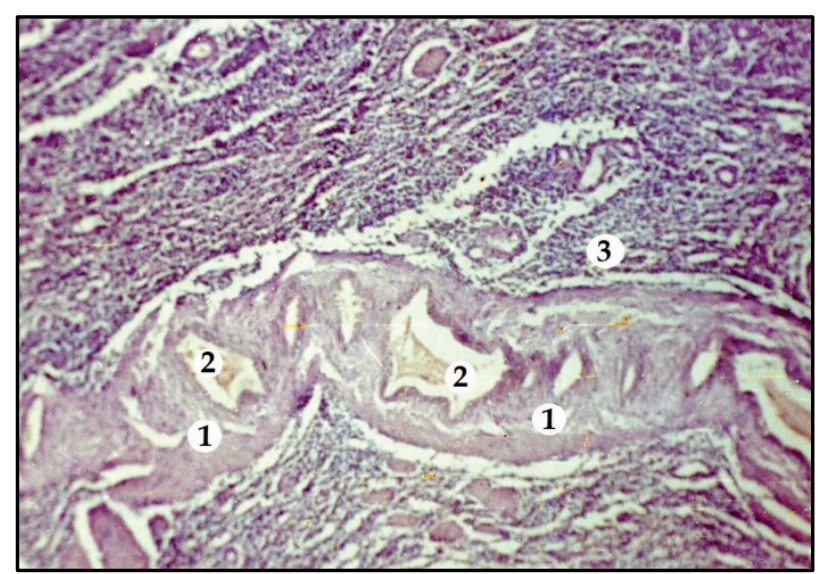

Fig. 2. Changes in vessels of the spleen in splenomegaly and the formation of specific complexes with sinuses of cavernous bodies: 1 - cavernous bodies, 2 - blood clots, obstructing vessels, 3 - spleen pulp; haematoxylin-eosin stain; $\times 160$

Vascular membranes were oedematous, walls were susceptible to destructuration and hyalinosis (Fig. 3).

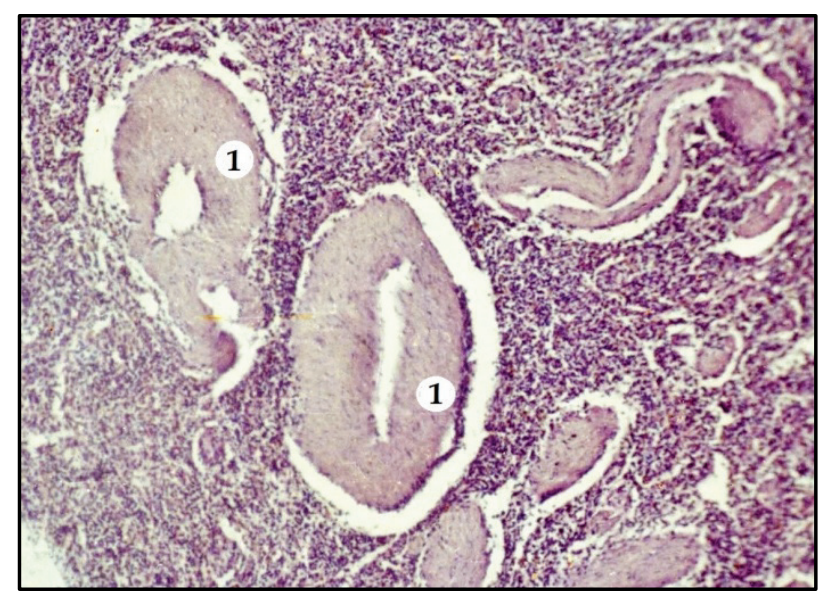

Fig. 3. Swelling and hyaline dystrophy of spleen vessel walls in the splenomegaly (1): haematoxylin-eosin stain; $\times 160$

When stained with the RBB method (Soroka et al., 2005), fibrin deposits were found in the spleen tissues. Thus, in connective tissue trabeculae, deposits of predominantly "old fibrin" (blotches of blue colour), with small blotches of "young fibrin" (purple colour) were noted (Fig. 4). In the walls of vessels, there were mainly deposits of "young fibrin" (Fig. 5, 6).

\section{Discussion}

The main pathogenic factor that plays a decisive role in the entire cascade of pathogenesis in babesiosis is the destruction of red blood cells under the influence of pathogens (Schetters et al., 2009; Solano-Gallego et al., 2016; Akel \& Mobarakai, 2016; Eichenberger et al., 2016).

In our earlier works (Dubova, 2020), it was shown that in acute babesiosis, the main complicating pathogenetic force is the DIC syndrome. The process affects all organs and systems, leading to functional disorders and organic changes. In all experimental dogs with acute babesiosis, clinical signs indicated the development of multiple organ pathology: haemolytic jaundice, intoxication syndrome, hepatitis, acute renal failure, gastroenterocolitis, cardiovascular failure, encephalopathy, and erythropathy. All these symptoms are due to the pathogenic effect of the pathogen (the intensity of parasitaemia is 6-10\%) and the development of DIC syn- 
drome (Schetters et al., 2009; Köster et al., 2015; Goddard et al., 2016; Holovakha et al., 2018; Dubova et al., 2020).

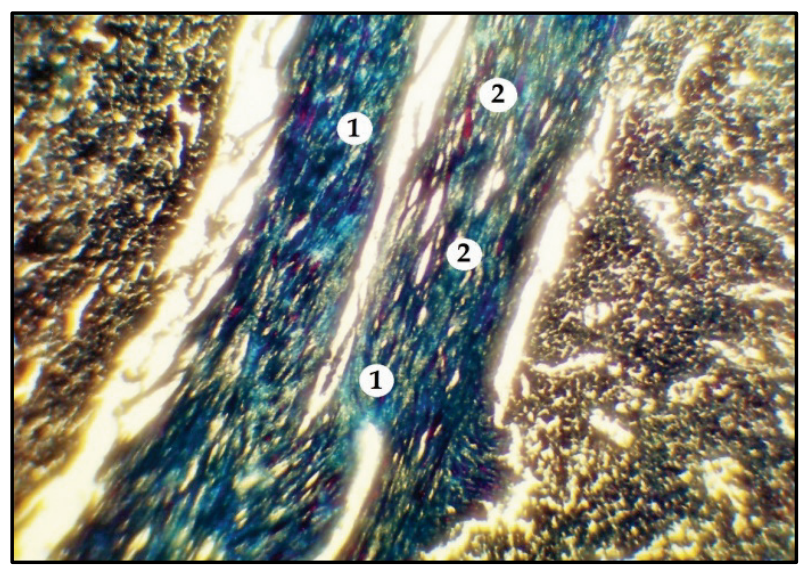

Fig. 4. Fibrin deposits in the structure of the spleen trabecula in splenomegaly: 1 - deposits of "old" fibrin, 2 - deposits of "young" fibrin; RBB stain; $\times 450$

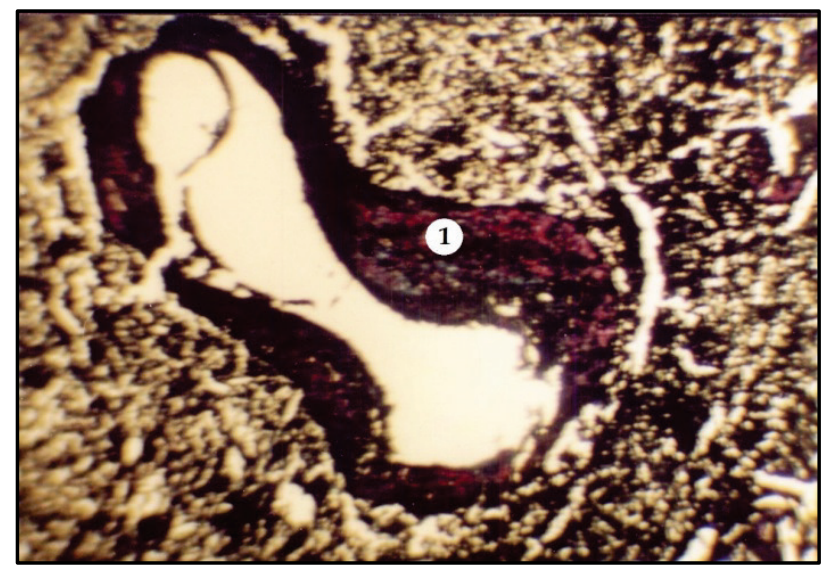

Fig. 5. Deposits of fibrin in the vessel wall of the spleen with splenomegaly: 1 -deposits of "young" fibrin; RBB stain; $\times 450$

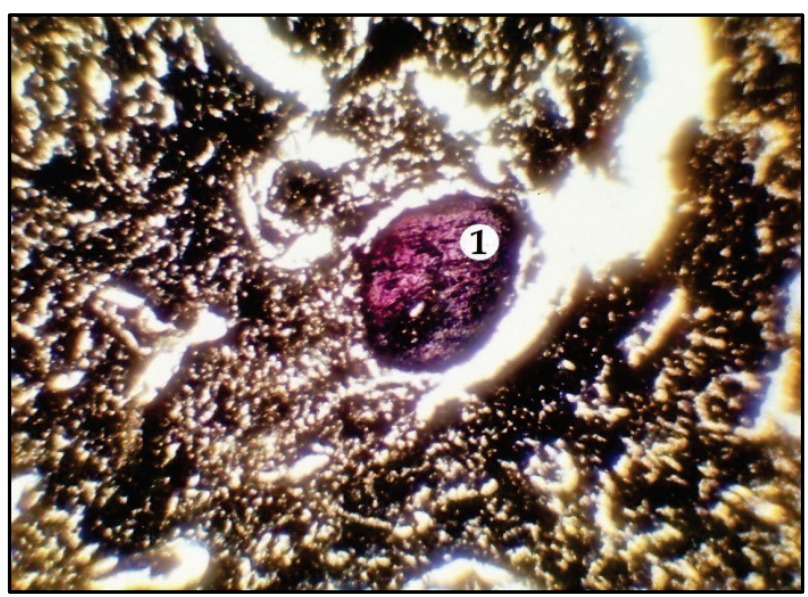

Fig. 6. Oedema and dystrophic changes in the spleen vessel wall with deposits of "young fibrin" $(I)$ in dog splenomegaly: RBB stain; $\times 450$

Despite therapeutic measures taken to destroy the pathogen, complications developed in some animals, which were identified as hypersplenism based on clinical and laboratory studies (Warkentin, 2018). Clinical signs established during this period indicated the development of intoxication syndrome and were not specific. The following changes were noted in the haematological profile: normochromic type anaemia, ESR acceleration, erythrocytopenia, leukocytopenia, and thrombocytopenia. The data obtained characterized cytopenia and were the basis for the diagnosis hypersplenism (Mohapatra \& Mishra, 2013; Warkentin, 2018).
It is known (Warkentin, 2018) that hypersplenism is a functional concept that reflects the hyperactivity of the spleen concerning blood corpuscles and their increased destruction. In its development, this process is accompanied by hyperplastic changes in the organ with loss of spleen functionality in the future. Ultimately, splenomegaly is an irreversible condition (Mohapatra \& Mishra, 2013; Dubova et al., 2019).

Splenomegaly is almost always accompanied by impaired blood flow in the portal vessels due to increased pressure in the splenic vein. As a result, portal hypertension develops, which is accompanied by varicose veins of internal organs, primarily the esophagus and stomach. This is a very dangerous syndrome from a prognostic point of view, which can cause critical conditions, in particular, bleeding and death (Kamath \& Shah, 2018). Naturally and often, splenomegaly is accompanied by hepatomegaly (Mohapatra \& Mishra, 2013; Kamath \& Shah, 2018).

A biochemical study of the blood of sick dogs with hypersplenism / splenomegaly manifestations revealed: hyperbilirubinemia $(\mathrm{P}<0.001)$ due to a predominantly conjugated fraction, a significant increase in the activity of transaminases AST, ALT, and GGT $(\mathrm{P}<0.001)$, hypoalbuminemia $(\mathrm{P}<0.001)$. Such indicators determine the development of liver failure in the form of hepatitis, inflammation of the biliary tract, impaired protein-synthesizing function of the liver (Kamath \& Shah, 2018).

The performed study of the DIC syndrome markers' block made it possible to establish: hypofibrinogenemia $(\mathrm{P}<0.001)$, a significant increase in the level of FDP including D-dimer, and SFMC $(\mathrm{P}<0.001)$. Thus, the main complicating process, which is the cause of irreversible changes in the spleen, was confirmed by laboratory tests. The indicators of the APTT and PT coagulation tests are multidirectional, which, against the background of the absence of clear clinical signs of the DIC syndrome itself, allowed us to classify its course as a "subacute stage of consumption coagulopathy" (Levi, 2018), in which both DIC pathogenic vectors hypercoagulation and hypocoagulation are simultaneously manifested (Levi, 2018; Dubova et al., 2020).

According to results of studies of hemodynamic blood parameters of dogs with complications after suffering babesiosis, a significant circulating blood deficit was established (41\%). Such a deficiency is considered severe and may indicate the development of irreversible haemorrhagic shock (Guly et al., 2011; Pacagnella et al., 2013; Vincent \& De Backer, 2013; Nathan et al., 2016; Timmermans et al., 2018; Hajjar \& Teboul, 2019; Ji \& Brown, 2019; Villa et al., 2019; Gupta \& Pinsky, 2020). In the case of splenomegaly due to the cytopenia that has occurred, as well as taking into account the development of DIC syndrome, which is always the pathogenetic axis of shock (Dubova et al., 2020), the irreversible haemorrhagic shock can become fatal for the dog's life. This condition determines the need for the urgent splenectomy in the order to eliminate the main source of the development of severe complications as well as further intensive care of the animal (Vincent \& De Backer, 2013; Timmermans et al., 2018; Dubova et al., 2020).

According to clinical indications, sick dogs underwent splenectomy, and the affected organ was subjected to further histological examination.

All samples showed a strong proliferation of connective tissue elements - the trabecular apparatus, vascular walls. In this case, the parenchyma of the organ was destructed, lymphatic formations were poorly expressed. It is known (Kage et al., 2019) that mainly mesenchymal dystrophies develop in the stroma of organs, as well as in the blood vessel walls, in particular, mesenchymal dysproteinoses. First, the mucoid swelling develops pathogenetically, and then the permeability of vascular walls increases. Plasma seeps through the blood vessels' walls and fibrin forms insoluble compounds with collagen fibres.

Figure 5 shows that elements of trabeculae contained more of the "old" fibrin, but there are also disseminations of the "young" fibrin. "Old" fibrin completely permeates the lymphatic follicle's blood vessel walls. In walls of the parenchyma vessels, mainly the "young" fibrin is deposited (Fig. 6). Such changes indicate that initially, elements of the stroma and lymphatic formation vessels are subject to disorganization, and later vessels of the parenchyma.

Further destruction of the collagen and plasmorrhage are the basis for the development of hyalinosis (Weinreb \& Rosenbloom, 2013; Kage et al., 2019), which is pronounced in the parenchyma blood vessel walls (Fig. 4). This dysproteinosis characterizes irreversible changes in the con- 
nective tissue. Thus, determining deposits of fibrin in the organ's structures characterize the organopathology of the DIC syndrome and determine the systemic response of the body with a tendency to irreversibility (Dubova et al., 2020).

Considering the "colour scale" of the distribution of fibrin by age of its deposition in tissues, it can be argued that the complication process is chronic, beginning even during the acute form of babesiosis (Köster et al., 2015; Dubova et al., 2020), and continues until the end of splenomegaly as an irreversible process.

In the development of splenomegaly, the process of fibrin deposition in the connective tissue elements begins with the stroma structures and lymphatic formation vessels, and later affects parenchyma vessels of the organ. Thus, the soaking of blood plasma into connective tissue elements is observed, which means that interstitial oedema develops in the spleen as a parenchymal organ. Pathogenetically, this process causes a decrease in effective circulating blood elements in the bloodstream (Levi, 2018; Dubova et al., 2020). In the continuation of the phenomenon of circulating blood volume deficit, they increase and cause the development of shock (Vincent \& De Backer, 2013; Timmermans et al., 2018), which, in turn, intensifies the DIC syndrome, forming a "vicious circle".

\section{Conclusions}

It can be concluded that in dogs after acute spontaneous babesiosis, within 7-10 days, hypersplenism / splenomegaly syndrome develops (the extent of manifestation is $8.3 \%$ ), which is confirmed by clinical general and special methods. During this period, haematological parameters are characterized by normochromic type anaemia and cytopenia. According to results of the biochemistry, liver failure in the form of hepatitis can be established, the inflammation of bile ducts, violations of protein-synthesizing function. Changes in hemodynamic parameters determine a severe deficit in circulating blood volume (41\%) and the development of decompensated haemorrhagic shock. Markers of haemostasis indicators (hypofibrinogenemia, significant increase in SFMC and FDP, including D-dimer, multidirectional indicators of APTT and PT coagulation tests) identify DIC syndrome at the stage of consumption coagulopathy. Histopathological studies indicate the development of mesenchymal dysproteinosis in connective tissue elements of the spleen. They are based on the deposition of fibrin during the entire process of splenic hyperplasia, which is an organo-pathological criterion for DIC syndrome.

\section{The authors declare the absence of any conflict of interest.}

The current studies are at the initiative of the authors and do not have any outside financial support. Research was carried out within the framework of the initiative topic for scientific work "Ecological and biological features of the development of invasive diseases in natural and semi-natural animal populations of the northern regions of Ukraine" (state registration No. 0121U109311).

\section{References}

Akel, T., \& Mobarakai, N. (2017). Hematologic manifestations of babesiosis. Annals of Clinical Microbiology and Antimicrobials, 16(1), 6.

Belousov, A., Malygon, E., \& Yavorskiy, V. (2017). Calculating the true volume of blood loss. Journal of Anesthesia and Clinical Research, 8(11), 787.

Bilić, P., Kuleš, J., Barić, R., \& Mrljak, V. (2018). Canine babesiosis: Where do we stand? Acta Veterinaria, 68(2), 127-160.

Boes, K. M., \& Durham, A. C. (2017). Bone marrow, blood cells, and the lymphoid/lymphatic system. In: Zachary, J. F. (Ed.). Pathologic basis of veterinary disease. 6th ed. Elsevier, Mosby, St. Louis. Pp. 724-804.

Briggs, C., \& Bain, B. J. (2017). Basic haematological techniques. In: Bain, B. J., Bates, I., \& Laffan, M. A. (Eds.). Dacie and Lewis practical haematology. $12^{\text {th }}$ ed. Elsevier, Philadelphia. Pp. $18-49$.

Dubova, O. A., Feshchenko, D. V., Bakhur, T. I., Zghozinska, O. A., Antipov, A. A., Rublenko, S. V., Goncharenko, V. P., Shahanenko, R. V., \& Shahanenko, V. S. (2020). Disseminated intravascular coagulation syndrome as a complication in acute spontaneous canine babesiosis. Macedonian Veterinary Review, 43(2), $141-149$.

Dubova, O. A., Zghozinska, O. A., Kovalyova, L. O., \& Kovalyov, P. V. (2019). Splenomegaliia iak uskladnennya, sprichinene babeziozom u sobak [Splenomegaly as a complication of dogs' babesiosis]. Bulletin of Poltava State Agrarian Academy, 2, 126-132 (in Ukrainian).
Eichenberger, R. M., Riond, B., Willi, B., Hofmann-Lehmann, R., \& Deplazes, P. (2016). Prognostic markers in acute Babesia canis infections. Journal of Veterinary Internal Medicine, 30(1), 174-182.

Goddard, A., Leisewitz, A. L., Kjelgaard-Hansen, M., Kristensen, A. T., \& Schoeman, J. P. (2016). Excessive pro-inflammatory serum cytokine concentrations in virulent canine babesiosis. PLoS One, 11(3), e0150113.

Goddard, A., Wiinberg, B., Schoeman, J. P., Kristensen, A. T., \& Kjelgaard-Hansen, M. (2013). Mortality in virulent canine babesiosis is associated with a consumptive coagulopathy. The Veterinary Journal, 196(2), 213-217.

Guly, H. R., Bouamra, O., Spiers, M., Dark, P., Coats, T., \& Lecky, F. E. (2011). Vital signs and estimated blood loss in patients with major trauma: Testing the validity of the ATLS classification of hypovolaemic shock. Resuscitation, 82(5), 556-559.

Gupta, G., \& Pinsky, M. R. (2020). What are the best tools to optimize the circulation? In: Deutschman, C. D., \& Neligan, P. J. (Eds.). Evidence-based practice of critical care. 3rd ed. Elsevier, Philadelphia. Pp. 351-358.

Hajjar, L. A., \& Teboul, J.-L. (2019). Mechanical circulatory support devices for cardiogenic shock: State of the art. Critical Care, 23(1), 76.

Ji, J., \& Brown, D. L. (2019). Distributive shock. In: Brown, D. L. (Ed.). Cardiac intensive care. 3rd ed. Elsevier, Philadelphia. Pp. 208-215.

Jobe, S. M., \& Di Paola, J. (2019). Congenital and acquired disorders of platelet function and number. In: Kitchens, C. S., Kessler, C. M., Konkle, B. A. (Eds.). Consultative hemostasis and thrombosis. 4th ed. Elsevier, Philadelphia. Pp. 145-166.

Kage, M., Kondou, R., \& Ogata, T. (2019). Anatomy of the spleen and pathology of hypersplenism. In: Obara, K. (Ed.). Clinical investigation of portal hypertension. Springer, Singapore. Pp. 25-34.

Kamath, P. S., \& Shah, V. H. (2018). Portal hypertension related to bleeding. In: Sanyal, A. J., Boyer, T. D., Lindor, K. D., \& Terrault, N. A. (Eds.). Zakim and Boyer's hepatology. 7th ed. Elsevier, Philadelphia. Pp. 233-261.

Kawasugi, K., Wada, H., Honda, G., Kawano, N., Uchiyama, T., Madoiwa, S., Takezako, N., Suzuki, K., Seki, Y., Ikezoe, T., Iba, T., \& Okamoto, K. (2021) Hypofibrinogenemia is associated with a high degree of risk in infectious diseases: A post-hoc analysis of post-marketing surveillance of patients with disseminated intravascular coagulation treated with thrombomodulin alfa. Thrombosis Journal, 19(1), 12.

Köster, L., Lobetti, R., \& Kelly, P. (2015). Canine babesiosis: A perspective on clinical complications, biomarkers, and treatment. Veterinary Medicine: Research and Reports, 6, 119-128.

Laffan, M. A., \& Manning, R. A. (2017). Investigation of haemostasis. In: Bain, B. J., Bates, I., \& Laffan, M. A. (Eds.). Dacie and Lewis practical haematology. $12^{\text {th }}$ ed. Elsevier, Philadelphia. Pp. 366-409.

Levi, M. (2018). Disseminated intravascular coagulation. In: Hoffman, R., Benz, E. J., \& Silberstein, L. E. (Eds.). Hematology. 7th ed. Elsevier, Philadelphia. Pp. 2064-2075

Michelson, A. D. (2019). The clinical approach to disorders of platelet number and function. In: Michelson, A. D., Cattaneo, M., Frelinger, A., \& Newman, P. (Eds.). Platelets. 4th ed. Academic Press, Elsevier, Cambridge. Pp. 701-705.

Mohapatra, S., \& Mishra, B. (2013). Splenomegaly. In: Mayer, J., \& Donnelly, T. M. (Eds.). Clinical veterinary advisor: Birds and exotic pets. Saunders, Elsevier, Philadelphia. Pp. 497-498.

Nathan, H. L., Cottam, K., Hezelgrave, N. L., Seed, P. T., Briley, A., Bewley, S., Chappell, L. C., \& Shennan, A. H. (2016). Determination of normal ranges of shock index and other haemodynamic variables in the immediate postpartum period: A cohort study. PLoS One, 11(12), e0168535.

Nguyen, A., Dasgupta, A., \& Wahed, A. (2016). Coagulation-based tests and their interpretation. In: Nguyen, A., Dasgupta, A., \& Wahed, A. (Eds.). Management of hemostasis and coagulopathies for surgical and critically ill patients. Elsevier, Amsterdam. Pp. 1-16.

Nyland, T. G., \& Mattoon, J. S. (2015). Spleen. In: Mattoon, J. S., \& Nyland, T. G. (Eds.). Small animal diagnostic ultrasound. 3rd ed. Saunders, Elsevier, St. Louis. Pp. $400-437$.

Pacagnella, R. C., Souza, J. P., Durocher, J., Perel, P., Blum, J., Winikoff, B., \& Gülmezoglu, A. M. (2013). A systematic review of the relationship between blood loss and clinical signs. PLoS One, 8(3), e57594.

Pantchev, N., Pluta, S., Huisinga, E., Nather, S., Scheufelen, M., Vrhovec, M. G., Schweinitz, A., Hampel, H., \& Straubinger, R. K. (2015). Tick-borne diseases (Borreliosis, Anaplasmosis, Babesiosis) in German and Austrian dogs: Status quo and review of distribution, transmission, clinical findings, diagnostics and prophylaxis. Parasitology Research, 114(S1), 19-54.

Rafaj, R. B., Kuleš, J., Selanec, J., Vrkić, N., Zovko, V., Zupančič, M., Trampuš Bakija, A., Matijatko, V., Crnoqaj, M., \& Mrljak, V. (2013). Markers of coagulation activation, endothelial stimulation, and inflammation in dogs with babesiosis. Journal of Veterinary Internal Medicine, 27(5), 1172-1178.

Roshal, M. (2013a). Prothrombin time. In: Shaz, B. H., Hillyer, C. D., Roshal, M., \& Abrams, C. S. (Eds.). Transfusion medicine and hemostasis: Clinical and laboratory aspects. 2nd ed. Elsevier, London. Pp. 799-803. 
Roshal, M. (2013b). Activated partial thromboplastin time. In: Shaz, B. H., Hillyer, C. D., Roshal, M., \& Abrams, C. S. (Eds.). Transfusion medicine and hemostasis. 2nd ed. Elsevier, London. Pp. 805-807.

Schetters, T. P. M., Kleuskens, J. A. G. M., Van De Crommert, J., De Leeuw, P. W. J., Finizio, A.-L., \& Gorenflot, A. (2009). Systemic inflammatory responses in dogs experimentally infected with Babesia canis: A haematological study. Veterinary Parasitology, 162, 7-15.

Schorn, M. N. (2010). Measurement of blood loss: Review of the literature. Journal of Midwifery and Women's Health, 55(1), 20-27.

Solano-Gallego, L., Sainz, Á., Roura, X., Estrada-Peña, A., \& Miró, G. (2016). A review of canine babesiosis: The European perspective. Parasites and Vectors, 9(1), 336.

Timmermans, K., Slagt, C., \& Kox, M. (2018). Hemorrhagic shock. New England Journal of Medicine, 378(19), 1850-1853.

Tutton, S. M., Nemcek, A. A., \& Vogelzang, R. L. (2008). Angiography and interventional radiology of the spleen. In: Gore, R. M., \& Levine, M. S. (Eds.). Textbook of gastrointestinal radiology. 3rd ed. Saunders, USA. Pp. 1983-1992.

Vannier, E., \& Krause, P. J. (2013). Babesiosis. In: Magill, A. G., Hill, D. R., Solomon, T., \& Ryan, E. T. (Eds.). Hunter's tropical medicine and emerging infectious disease. 9th ed. Saunders, USA. Pp. 761-763.
Villa, G., Ricci, Z., \& Romagnoli, S. (2019). Hemodynamic support in the critically ill patient. In: Ronco, C., Bellomo, R., Kellum, J. A., \& Ricci, Z. (Eds.). Critical care nephrology. 3rd ed. Elsevier, Philadelphia. Pp. 21-25.

Vincent, J.-L., \& De Backer, D. (2013). Circulatory shock. New England Journal of Medicine, 369(18), 1726-1734.

Vishwakarma, P., \& Nandini, M. K. (2019). Overview of canine babesiosis. In: Bekoe, S. O., \& Saravanan, M. (Eds.). Veterinary medicine and pharmaceuticals. IntechOpen, London. Pp. 1-17.

Wahlang, L., Lakshmanan, B., Thomas, N., Bosewell, A., Jose, J., Chulliyil, S., \& Thazhathuveetil, A. (2019). SYBR green-based real-time PCR detection of canine Babesia spp. in ixodid ticks infesting dogs in Kerala, South India. Turkish Journal of Veterinary and Animal Sciences, 43(3), 427-431.

Warkentin, T. E. (2018). Thrombocytopenia caused by platelet destruction, hypersplenism, or hemodilution. In: Hoffman, R., Benz, E. J., Silberstein, L. E. (Eds.). Hematology. 7th ed. Elsevier, Philadelphia. Pp. 1955-1972.

Weinreb, N. J., \& Rosenbloom, B. E. (2013). Splenomegaly, hypersplenism, and hereditary disorders with splenomegaly. Open Journal of Genetics, 3(1), $24-43$. 